\title{
Designing and Researching Virtual Learning Communities
}

http://dx.doi.org/10.3991/ijet.v7i4.2311

\author{
A. Santos \\ Universidad de las Américas Puebla, Cholula, México
}

\begin{abstract}
This article describes, with a basis in educational literature, some of the main characteristics of learning communities. In addition, a list of instructional strategies is proposed to create a virtual learning community within a traditional academic course. These strategies are then integrated into a proposed research design to study and evaluate this particular type of learning and know what questions to ask, what data to collect, and how to analyze them.
\end{abstract}

Index Terms-Communities of Learning, Virtual Learning Communities, Virtual Learning Environments, Virtual Worlds.

\section{INTRODUCTION}

Learning communities have distinctive characteristics which set them apart from most other ways of learning. Although learning communities behave differently than do other, more traditionally organized types of learning environments, they are often erroneously treated as the same. For example, interactive experiences in which students' discussions are motivated by an online forum or in which students collaboratively create an academic paper in an electronic platform like Google Docs could be considered learning environments, but are not necessarily learning communities. In the present paper I will be explaining why I believe that these two examples, although pertinent illustrations of individuals interacting together, should not be automatically regarded as learning communities because they may lack some of the particular internal learning and social dynamics that characterize learning communities.

Considering these ideas, the main objective of this paper is to describe, in light of the educational literature, some of the main characteristics of learning communities, what gives them their particular internal social dynamics and what sets them apart from other types of learning environments. Also, a list of instructional strategies is proposed to create a virtual learning community which could be used as part of the teaching methods employed in a traditional academic course, strategies that are then integrated into a proposed research design to study this special type of learning and know what questions to ask, what data to collect, and how to analyze them.

\section{BACKGROUND}

Basically, a learning community is formed when a group of individuals decides to collaborate in order to achieve a common goal, expanding, along the way, their knowledge base with regard to related topics. This simple definition encapsulates one of the main features of a learning community; that is, that learning communities and their unique dynamics emerge naturally when humans follow the rather natural tendency to gather with others to solve common problems, documenting and placing value on the knowledge that is gained during these processes. This is a natural social way of knowing, which humans have been using throughout their existence, characterized not by, "... an individual experience, but one of exchanging and contributing to the knowledge of a community." [1]. Thus, from this perspective, we can conceptualize knowing, learning, and cognition as social constructions [2] and communities as places where people share in knowledge construction in order to obtain a common goal by interacting in their own particular ways [3]. For this reason, learning within a community is necessarily characterized by what [4] conceptualize as socially shared cognition; this is a socio-cultural constructivist notion that puts forth the idea that, in any group activity, there is your cognition (your knowledge), my cognition (my knowledge), and our cognition (community knowledge). This concept of socially shared cognition or community knowledge can be further explained using the analogy of a group of animals that, due to their individual sight limitations, decide to form a herd and move together in order to have a 360-degree view of their surroundings. In this example we could say that a herd of animals possesses a socially shared vision, which develops because they are acting together. Individually, they are not capable of a 360degree view, but as a group they are; this augments their survival abilities because they come to be more able to easily spot prey or incoming predators. A similar situation emerges when humans, also following basic instincts, join together to solve problems; that is, a socially shared cognition is created which augments our general abilities to address problems. Here lies the most important feature of a learning community.

Schwier [5] discusses the characteristics of communities thoroughly; for this author, in a direct and simple way, communities are, "...collections of individuals who are bound together for some reason," and are characterized as being resilient, hospitable, multifaceted and as having life cycles. He describes communities as resilient because he sees them as organic entities that recover quickly, and further states that, "...communities cannot be created; rather they emerge when conditions nurture them," [5]. The author also affirms that communities are hospitable; this is logical in that communities must be amiable environments with clear codes of conduct in order to permit learning based to take place as a result of risk taking. In fact, this is the type of learning that is desired and needed 
for the success and continuance of a community. For Schwier [5], communities are also multifaceted entities because they usually have more than one focus, for example, a community focused on social development may also have a strong political agenda. Finally, he suggests that communities have life cycles; that is, they evolve, they go through increasing stages of participation and then they decline. In this sense, the author states that communities traditionally go through three stages: 1) a formative stage, when strong leadership is critical so that the community can clarify its main purpose and build its own ways of working together; 2) a mature stage, during which, “...the purpose, shape, and operations of the community are settled."; at this second stage, leadership importance diminishes because members themselves are now taking charge of things; finally, 3) a decline stage during which most communities, due to internal and external forces, are challenged to reinvent themselves and to question their original purposes. What happens during the final stage is that some more traditional members come to be strongly opposed to drastic changes, while other, more innovative members strive for new goals. These opposing forces eventually may cause the community to dissolve or to be converted into something else.

Another author who has done extensive work in this area is Etienne Wenger, who uses the term communities of practice and defines them as, "groups of people informally bound together by shared expertise and passion for a joint enterprise," [6]. He further states [7] that communities of practice have three characteristics: 1) members must share a common interest, which defines their main identity as a community; 2) members must constantly engage in social activities that allow for the construction of mutual knowledge; and 3) members, through their practices, must build a shared knowledge base. Reference [8] describes a process to explain how members integrate into a community of practice, which the authors call Legitimate Peripheral Participation, where newcomers' participation becomes more and more complete as they move from peripheral to full participation, learning and interacting along the way with more experienced members.

Santos [9], after revising several key studies and authors within the social approach to learning, and learning communities in particular, reports that in learning communities: 1) although members declare their common domain of interest when starting a learning community, usually this central interest changes during the lifetime of a community; 2) members constantly engage in collaborative problem solving activities where they freely propose diverse viewpoints, negotiate, discuss, reflect and share information; 3) to sustain their relevant activities and a sense of mutual trust, members need sufficient administrative and technical support as well as ample communication resources; 4) members need to constantly document their practices so that they can build a sound information base that can be consulted by all the members and even by other, similar communities; 5) members assume different roles throughout the lifetime of a community, for instance, newcomers learn as Legitimate Peripheral Participants and evolve over time to become experts; 6) members sometimes form sub-groups within the larger community to seek more personal goals; and 7) members remain part of the community for as long they feel that they are achieving their personal learning goals.

\section{STRATEGIES FOR CREATING VIRTUAL EDUCATIONAL ENVIRONMENTS}

Taking into consideration the ideas presented above, in this section a set of four strategies or instructional suggestions will be discussed with the purpose of assisting in the process of designing virtual learning communities in schools and universities. The aim is not to give rigid recipes for implementation, but rather to reflect on some relevant guidelines regarding the building of successful learning communities and how to apply them as part of academic courses when we wish our students to have this type of learning.

Strategy 1: permit the social dynamics that characterize a learning community.

Because learning communities naturally emerge, they cannot be artificially created. This asseveration may present an apparent contradiction when we wish to start a learning community as part of our teaching strategies in one of our more traditionally organized courses. That is, if we purposely start a virtual learning community for our students based around a given learning objective, then this experience cannot be a real learning community, according to the literature, because it will have been artificially created. The solution lays in the reflection that, although we would not have a learning community in the traditional sense, we could still develop an effective learning experience if we allowed and even encouraged the social dynamics that are sought in traditional learning communities. To accomplish this, after creating the virtual community as well as all of its components, we must first of all leave out some of our more traditional beliefs about what constitutes a teaching and learning experience. For example, when needed, teachers must be ready to modify their more traditional status of directors of the process and be willing to participate as members of the community (although in the role of expert). Also, teachers must make strong efforts to create an amiable virtual environment in which the environment's code of conduct is clear from the start, and in which there is administrative and technical support as well as access to multiple communication resources for the students. The aim is to make students feel safe to take risks while proposing innovative ways to solve a given problem. In addition, students must be allowed to participate as newcomers and be immersed in the dynamics of learning as legitimate peripheral participants interacting with the experts (teachers and more advanced peers) so that they can increase their own expertise. They must also be given much more freedom to create, choose and decide with whom, when and how to fulfill the tasks they perform within the community.

Strategy 2: allow learning communities to have their own life cycles.

Learning communities need time before they can reach the stage at which most of their members are fully engaged in the kind of social activities that result in the kind of learning and knowledge desired. This characteristic presents a difficult challenge when one has only one semester to complete a learning task within a learning community. However, using the three stage model proposed by Schwier [5] mentioned above, we can suggest a basic model to create and sustain a learning community even during a shorter course; that is: 
Stage 1: the teacher is the leader. After designing and creating a virtual environment and starting the activities within it, the teacher must clearly be the leader of the project giving all the necessary regulations to his or her students. She must make sure that her students: 1) have the technical expertise to navigate the virtual environment, for example in Second Life it is critical to know how to move one's avatar in the 3D environment; 2) understand what their roles are in the community and how to perform them, for instance they can be told that they are going to be part of a scientific group that must solve environmental problems using whatever is available to them; and 3) understand the learning objective around which the learning community is built; for example, to propose ways of solving the world's economic crisis, or design a new laboratory to be constructed on the surface of the moon. This third point is a key issue because, for a real community of learning to take place, the learning objective must be highly valued by the students as something worth doing.

Stage 2: the students are the leaders. After several working sessions inside the virtual community, students begin to clearly understand what they are expected to achieve as members of the community; although some may need more time than others. From this moment on, the teacher must retreat slightly from her leading role and allow her students to move as freely as they want or need; for example, she must allow them to choose the path they want to follow in order to solve the problem at hand, or choose how to organize a working team. Of course her role continues to be that of an expert on the subject matter and on how to solve these types of problems. She must be available to answer questions and, on occasions, to model skills, to show how some things should be done. Each different team of students must be allowed the go through this second stage at their own pace (within the time limits of the academic period, of course). Some groups will decide very rapidly that they have already achieved the learning goal while others will take a longer path to the learning goal. These differences are expected and accepted as normal behavior in learning communities.

Stage 3: offline activities start. After students begin to feel that they have achieved the tasks they were asked to fulfill, they can leave the virtual learning community and present their experience and results to the rest of the group. These presentations have an evaluation purpose of course, but they also serve to aid in learning since students are able to articulate their thoughts, draw conclusions and reflect and interpret their own learning process. In addition, as part of Stage 3, the transfer of learning must be promoted; to achieve this, it is important that students are offered opportunities to apply what they have learned in the virtual community to other learning situations where they must solve somehow similar problems happening in different contexts.

Strategy 3: members of the community engage collaboratively in problem solving activities.

Learning in a community is a rather different experience than sitting individually in a regular classroom listening and taking notes. Students enter a learning community and are immediately engaged in collaborative activities related to a common interest (normally linked with the solution of a shared problem). During this process they must be allowed to collaboratively discuss, reflect and share all kinds of information; in this way they are engaging in the type of socially shared cognition that is desired in learning communities and obtain 360-degree cognition.

Strategy 4: encourage students to build a shared information base.

When performing activities collaboratively in a learning community, all kinds of information are produced. Students must be encouraged to document all they do at all times. Thus, members should have access to the necessary technical resources to do so; for example, each team can develop their own blog and should be able to access it at any time when interacting in the virtual world. Technically speaking, this is something that can be easily done in a virtual world like Second Life. In this way, they build information bases that can be consulted when needed and which can also be used by the teacher for evaluation purposes. Learning can be evaluated at all times by the teacher using the following data sources: 1) the teacher's own notes taken during the experience; 2) the teams' blogs; 3) the face-to-face presentations to the rest of the group; and 4) the solution each team created and documented to solve the problem.

\section{RESEARCH DESIGN TO STUDY AND EVALUATE VIRTUAL LEARNING COMMUNITIES}

As can be seen in the previous sections of this article, interacting in a community has such distinctive characteristics that a special dynamic is developed which fosters a special social way of knowing and learning. Furthermore, if we conceptualize learning in a virtual community "as a process distributed across avatars, the environment, and the learning activities in which they engage." [10], then, it is highly recommended that research carried out in order to study learning communities should mainly focus on understanding how this complex social dynamic within the environment transpires.

Bearing this last asseveration in mind, the first suggestion for a research design in learning communities would be to study it as a social phenomenon and not as an individual process; that is, to use the community itself as the unit of analysis and not the individual. This research decision is congruent with the situated paradigm discussed before because, as Gee [11] eloquently explains, in the situated cognition perspective, learning is conceptualized as something that "... is not just a matter of what goes on inside people's heads but is fully embedded in (situated within) a material, social, and cultural world." Considering this social perspective, although both quantitative and qualitative research designs could be used, a more qualitative perspective would be more advisable. For example, the use of an ethnographic design would be recommendable because it encompasses research, “...procedures for describing, analyzing, and interpreting a culture-sharing group's shared patterns of behavior, beliefs, and language that develop over time." [12]. A learning community is a culture-sharing group that has its own behavioral patterns, such as the ways members solve problems or the ways they use tools and terminologies. Hence, in line with the qualitative paradigm, data collection methods like semistructured in-world interviews, non-participant or participant observations, focus group or network analyses, etc. can be used inside the virtual world; this data can then be used to describe, analyze and interpret what is going on in the culture-sharing learning community. From a very 
general perspective, this last question (What is going on in a culture-sharing learning community?) would be the suggested focus of inquiry (according to the qualitative concept of Lincoln and Guba, [13]) for a research project in learning communities.

Secondly, to have a more practical model from which the dynamics and variables of a learning community can be identified, in conjunction with the ethnographic perspective, the basic systems organization of structure and processes can be employed. That is, to facilitate the study of a learning community we can conceptualize it as a social phenomenon with its own structures where processes are performed to achieve a goal. The purpose is to be able to identify the elements that form a given learning community in terms of its structures and its consequent social processes to better organize a research project. As can be seen in Fig. 1, all kind of structures are formed in a learning community; each one characterizing and sharing different types of processes.

Within a learning community, the most basic social structure that usually develops is the continuum that is formed based on the range of expertise of the community's participants. This continuum has novices or newcomers in one extreme and experts or old timers in the other. In a learning community, this is a key structure because it allows for the type of learning processes where novices learn, from the start, by doing activities with more expert members (teachers and more knowledgeable peers). This kind of human interaction allows novices to move from the periphery into the main flow of the whole community, eventually becoming experts [8].

Other important structures are, on the one hand, the cognitive scaffolding that the teacher builds to guide and support the students' learning using coaching and supervision actions such as questions, prompts, feedback, etc. This guide and support scaffolding also permits the crucial initial process of clarifying what the community's purpose will be, which in turn gives coherence to all of the activities done in the community. In a traditional course, it is expected that, from the start, the teacher proposes the community's purpose in the form of a learning outcome; however, the teacher must keep an open attitude and allow for all the possible changes that students could offer in view of their own interests. On the other hand, the structure of the virtual world's technical resources, which encourages the community's members to engage in processes like communicating, interacting, performing activities and using all the technical and pedagogical resources available to them, always documenting most of their activities along the way.

Another key structure is formed by the actions and interactions that students and teams perform. Students assume different social roles, which affect the ways teams form and interrelate. For example, some students immediately start to organize their team's activities, while others prefer to wait and learn more about the problem at hand before proposing any type of activity. These students' personal preferences during collaborative participations simultaneously influence the ways that teams work and self organize, and thus a hierarchy among teams also starts to emerge. This can happen, for instance, because some teams are more proactive than others and thus the other teams tend to look at what they are doing before attempting anything. This type of behavior is perfectly acceptable, by allowing it to happen we are respecting every team's

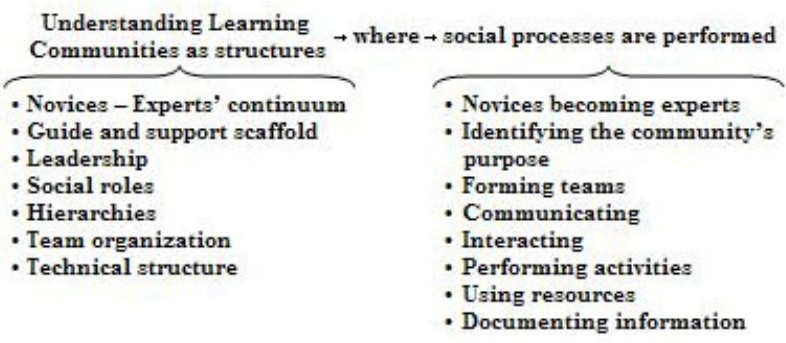

Figure 1. Structure and processes of a learning community for a research design.

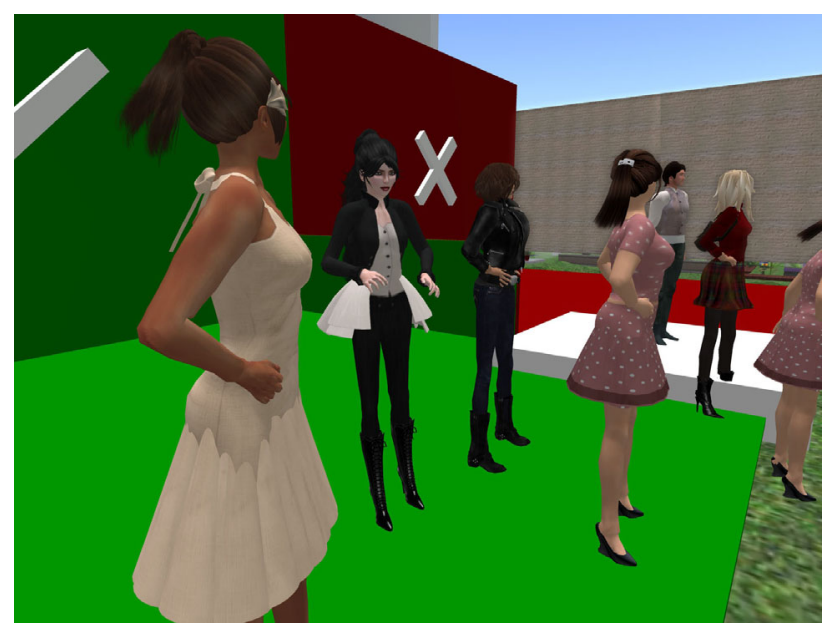

Figure 2. Students forming teams in a virtual world.

and student's own way of learning. Therefore, to ease the processes related with these structures, to begin with, students should be told that they must work as part of a team inside the virtual world. This can be a difficult and time-consuming experience inside a virtual world, thus enough time must be allowed so that students can become familiar with one another's identities as avatars before they start deciding which team they will be working on. Of course, the teacher can select the different teams in advance and save time; however, if students self-organize, this can serve as a way to get them to know each other's avatars better and also to polish the necessary abilities to move at ease inside a virtual world (See Fig. 2).

In summary, from this perspective, to study a given learning community as a social phenomenon and as a set of structures and processes, three basic research questions can be stated: 1) how are the community's social structures being created?; 2) how are the social processes happening?; and 3) how are these structures and processes evolving over time? Although discussing any specific research methodology in detail would be beyond the scope of the present article, a basic design for a research project is presented below, based on these four points:

\section{Stating research questions}

As stated before, because the essence of learning in a community is related to its members' social interactions, it is important to understand how these social processes happen so that they can be better nurtured. Therefore, initially the researchers should decide which structures, with their corresponding processes, they want to study and also if the study should be longitudinal. Table 1 presents a possible set of structures, processes and their corresponding research questions. As said before, the relationship 
between processes, structures, and questions is not one to one, thus, depending on the type of research project at hand, different sets of points can be identified.

2. Selecting and applying data collection methods

This depends on the type of research design selected by the researcher, if a qualitative design is decided on then, as stated before, techniques such as semi-structured interviews, non-participant or participant observations, focus group or network analysis can be used. What is important to stress here is that these data gathering methods can be used within a given virtual world; for example, the researcher's avatar can do field work observing and documenting within the virtual world.

3. Analyzing and interpreting data

Again, if a qualitative design is selected, methods like theme identification and the constant comparative method can be used to inductively identify categories within the gathered data. The set of categories found inductively would answer the previously stated focus of the inquiry: what is going on in a given learning community?

4. Iterating the process

For a research agenda in virtual communities it is very relevant to understand how a community evolves over time; thus the previous research procedure could be applied several times to produce a set of individual snapshots corresponding to several states of the community along a time line. Then, analyzing these different states, the whole life cycle of a learning community can emerge in terms of how its social structures and processes evolve over time.

This iterating method is congruent with the research approach called design-based research, which iteratively aims to test and improve a certain instructional design, generating theory along the way [14] because the method also revise the learning theory on which the design was based.

\section{CONCLUSIONS}

Learning has been an essential part of our everyday life throughout our existence. Throughout history, humans have always dedicated time to understanding how learning happens because we know how important it is for our survival. We have offered many explanations, from viewing learning as a set of simple stimuli and responses to viewing it as a complex social cognitive process. However, in all these explanations we have always acknowledged that the use of technology is an essential component of the learning process. That is why understanding how certain new technologies could facilitate learning has also been an important challenge.

The goal of the present article has been to contribute to achieve this challenge by defining and stating the pedagogical characteristics of virtual learning communities that set them apart from most other ways of learning. To ground these characteristics, a list of instructional strategies was proposed to create a virtual learning community and, finally, a research design, in terms of structures and processes, was described to study and evaluate this complex way of learning.
TABLE I.

AN EXAMPLE OF STRUCTURES, PROCESSES AND POSSIBLE RESEARCH QUESTIONS

\begin{tabular}{|c|c|c|}
\hline Structures & Processes & Research Questions \\
\hline $\begin{array}{l}\text { Novices - } \\
\text { Experts } \\
\text { continuum }\end{array}$ & Novices becoming experts & $\begin{array}{l}\text { How are novices } \\
\text { becoming experts? } \\
\text { How are novices and } \\
\text { experts interacting? }\end{array}$ \\
\hline $\begin{array}{l}\text { Guide and } \\
\text { support } \\
\text { scaffolding }\end{array}$ & $\begin{array}{l}\text { Identifying the commu- } \\
\text { nity's purpose } \\
\text { Forming teams } \\
\text { Communicating } \\
\text { Interacting } \\
\text { Performing activities } \\
\text { Using resources } \\
\text { Documenting information }\end{array}$ & $\begin{array}{l}\text { How do members } \\
\text { understand their } \\
\text { community's purpose? } \\
\text { How is supervision } \\
\text { being provided by the } \\
\text { teacher? } \\
\text { How do students use } \\
\text { the community's } \\
\text { resources to form } \\
\text { teams? } \\
\text { How are the activities } \\
\text { that students engage in } \\
\text { supported? }\end{array}$ \\
\hline Leadership & $\begin{array}{l}\text { Novices becoming experts } \\
\text { Communicating } \\
\text { Interacting } \\
\text { Performing activities }\end{array}$ & $\begin{array}{l}\text { How is leadership } \\
\text { being shared? } \\
\text { How do leaders } \\
\text { emerge? } \\
\text { How do their roles } \\
\text { change over time? } \\
\text { How do students decide } \\
\text { to form teams? } \\
\text { What is the level of } \\
\text { participation (motiva- } \\
\text { tion) among members? }\end{array}$ \\
\hline $\begin{array}{l}\text { Social roles } \\
\text { and hierar- } \\
\text { chies }\end{array}$ & $\begin{array}{l}\text { Communicating } \\
\text { Interacting } \\
\text { Performing activities }\end{array}$ & $\begin{array}{l}\text { How are members } \\
\text { communicating } \\
\text { between one another? } \\
\text { How does the students' } \\
\text { hierarchy form in each } \\
\text { team? } \\
\text { Which channels do } \\
\text { they use and how do } \\
\text { they use them? } \\
\text { What types of human } \\
\text { interactions are hap- } \\
\text { pening? (Negotiations, } \\
\text { discussions, reflections, } \\
\text { storytelling, sharing } \\
\text { information, etc.) }\end{array}$ \\
\hline $\begin{array}{l}\text { Team } \\
\text { organiza-tion }\end{array}$ & $\begin{array}{l}\text { Forming teams } \\
\text { Communicating } \\
\text { Interacting } \\
\text { Performing activities }\end{array}$ & $\begin{array}{l}\text { What is the hierarchy } \\
\text { between teams like? } \\
\text { What is the interaction } \\
\text { between teams like? } \\
\text { How do teams commu- } \\
\text { nicate? }\end{array}$ \\
\hline $\begin{array}{l}\text { Technical } \\
\text { structure }\end{array}$ & $\begin{array}{l}\text { Using resources } \\
\text { Documenting information }\end{array}$ & $\begin{array}{l}\text { How do members } \\
\text { interact with the } \\
\text { technical resources } \\
\text { provided to them? } \\
\text { How do members } \\
\text { document the informa- } \\
\text { tion that they are } \\
\text { producing? } \\
\text { How are technical } \\
\text { resources being used? }\end{array}$ \\
\hline
\end{tabular}




\section{SHORT PAPER}

\section{DESIGNING AND RESEARCHING VIRTUAL LEARNING COMMUNITIES}

\section{REFERENCES}

[1] E. C. Wenger, "Knowledge management is a donut: shaping your knowledge strategy with communities of practice". Ivey Business Journal, January, 2004, pp. 1-8.

[2] J. Lave, "Situating learning in communities of practice," in Socially shared cognition, L. B. Resnick, J. M. Levine and S. D. Teasley, Eds. Washington, D.C.: American Psychological Association, 1991, pp. 63-82. http://dx.doi.org/10.1037/10096-003

[3] L. B. Resnick, "Shared cognition: Thinking as social practice," in Socially shared cognition, L. B. Resnick, J. M. Levine and S. D. Teasley, Eds. Washington, D.C.: American Psychological Association, 1991, pp. 1-20.

[4] L. B. Resnick, J. M. Levine and S. D. Teasley, Socially shared cognition. Washington, D.C.: American Psychological Association, 1991. http://dx.doi.org/10.1037/10096-000

[5] R. A. Schwier, "A typology of catalysts, emphases, and elements of virtual learning communities," in Online learning communities, R. Luppicini, Ed. Charlotte, NC: Information Age Publishing, 2007, pp. 17-39.

[6] E. C. Wenger and W. M. Snyder, "Communities of practice: the organizational frontier." Harvard Business Review, JanuaryFebruary, 2000), pp. 139-145.

[7] E. C. Wenger, R. McDermott and W. M. Snyder, Cultivating communities of practice, Boston, MA: Harvard Business School Press, 2002.

[8] J. Lave and E. C. Wenger, Situated learning: Legitimate peripheral participation, Cambridge, UK: Cambridge University Press, 1991. http://dx.doi.org/10.1017/CBO9780511815355
[9] A. Santos, "Learning in virtual worlds: A situated perspective," in Teaching through multi-user virtual environments: Applying dynamic elements to the modern classroom, G. Vincenti and J. Braman, Eds. Hershey, PA: IGI Global, 2010, pp. 120-138. http://dx.doi.org/10.4018/978-1-61692-822-3.ch008

[10] A. Santos, "Using Design-Based Research for Virtual Worlds Research Projects." Journal of Virtual Worlds Research, vol. 3, no. 1, October, 2010, [Online]. Available: https://journals.tdl.org/ jvwr/article/view/824/886 [Accessed: November 2010].

[11] J. Gee, What video games have to teach us about learning and literacy, New York, N.Y.: Palgrave Macmillan, 2007.

[12] J. Creswell, Educational research: planning, conducting, and evaluating quantitative and qualitative research, Boston, MA: Pearson, 2012.

[13] Y. Lincoln and E. Guba, Naturalistic inquiry, Beverly Hills, CA.: Sage, 1985.

[14] A. L. Brown, "Design Experiments: Theoretical and methodological challenges in creating complex interventions in classroom settings." Journal of the Learning Sciences, vol. 2, no. 2, pp. 141178, 1992. http://dx.doi.org/10.1207/s15327809jls0202_2

\section{AUTHOR}

A. Santos is with the Department of Education, Universidad de las Américas Puebla, Cholula, México (email: antonio.santos@udlap.mx).

Received 16 October 2012. Published as resubmitted by the author 3 December 2012. 